Brit. J. prev. soc. Med. (1976), 30, 225-230

\title{
Low mortality rates in industrial cohort studies due to selection for work and survival in the industry
}

\author{
A. J. FOX AND P. F. COLLIER \\ Office of Population Censuses and Surveys and the Employment Medical Advisory Service, \\ Health and Safety Executive, London
}

\begin{abstract}
Fox, A. J. and Collier, P. F. (1976). British Journal of Preventive and Social Medicine, 30, 225-230. Low mortality rates in industrial cohort studies due to selection for work and survival in the industry. Occupational groups are often described as being relatively healthy because their mortality rates are lower than those of the national average. Although correct this confuses the issue for those who are interested in assessing the effects of exposure to a particular chemical. In a further analysis of data collected in a study of all men ever exposed to vinyl chloride monomer in the manufacture of polyvinyl chloride in Great Britain, three factors have been shown to contribute to the low mortality rates that were observed. The three factors: the selection of a healthy population for employment, the survival in the industry of the healthier men, and the length of time that this population has been pursued, have been quantified. The mortality experience within five years of entering this industry was shown to be as low as $37 \%$ of that expected; for circulatory disease and respiratory disease it was as low as $21 \%$. There was a progressive increase in standardized mortality ratio with the length of time since entry so that the effect had almost disappeared 15 years after entry. To avoid confounding the selection effect with the survival effect the latter was measured by separating men who survived 15 years after entering the industry according to whether or not they were still in the industry after this period. Those who had left experienced an overall standardized mortality ratio some $50 \%$ higher than those still in the industry. This effect, although consistent in the age groups between 25 and 74 years and for all cause groups studied, was greatest in those aged between 25 and 44 years and for lung cancer and respiratory disease.
\end{abstract}

Since the middle of the nineteenth century, when the first census was conducted in England, the number of persons dying in a particular year has been compared with the population for that year in order to derive estimates of annual death rates. William Farr (1864), in the Supplement to the 25th Annual Report of the Registrar-General of Births, Deaths, and Marriages in England, recognized the use that could be made of additional information, particularly the occupation recorded on the death certificate. He commented on 'the considerable difficulty in determining the mortality and the duration of life among men of all the professions, owing to the uncertainty in the naming of the trades'. Some occupations were considered as well defined and mortality rates were calculated for these. The hazards to the miner from explosions and underground injuries and to the publican from the effects of alcohol were clearly demonstrated.

William Ogle (1885), in his commentary in the Supplement to the 45th Annual Report, described two difficulties encountered in the calculation of death rates in different industries. The first was a consequence of the "considerable standard of muscular strength and vigour to be maintained' by those who pursued various trades and occupations. Once the individual's health or strength fell below this standard he was compelled to give up the 
occupation and either seek labour to which he was more suited, or in particularly serious cases, retire altogether from work. The second 'very serious flaw' was due to the fact that industries did not start on equal terms. The Supplement to the 75th Annual Report commented that 'some occupations may repel, while others attract, the unfit at the age of starting work, and, conversely some occupations may be of necessity recruited from men of supernormal physical condition'. It was thought that both these defects told in the same direction, giving an unfair advantage to such industries as required particular standards in the men they employed.

In contrast with the Registrar General's approach comparing the number of deaths and the estimated population, many recent studies have been based on tracing the mortality experience of defined cohorts. Although more accurate in terms of calculated death rates, these studies still suffer from the same difficulties with respect to their interpretation.

This problem has been widely recognized but no satisfactory solution proposed. Goldsmith (1975) pointed to five recent mortality studies which compared the observed mortality in an employed group with that expected on the basis of the general population or a non-exposed group. Most industrially-employed cohorts should be expected to have (and most do have) a better life expectancy than non-employed persons who include those in institutions, those with unstable employment, and those already ill at the time job-seeking begins. Goldsmith suggested that the bias might be greater at different ages and for certain causes but he concluded that the relevant data were not available. Enterline (1975) and Gaffrey (1975) both supported the suggestion that the effect was cause-related and Enterline proposed using a method of internal comparison.

McMichael, Haynes, and Tyroler (1975) pointed out that in the report referred to by Goldsmith the 'healthy worker effect' had been described but that it was accepted that none of the three approaches used-that is, local controls, proportional mortality ratios, and analysis of each plant separately to see if the same conclusions could be drawn-tackled this problem.

In both Goldsmith's letter and the replies referred to above, the problem was described as though there was only one property of occupational cohorts that should be measured. It is however clear from the comments made by Ogle that there are at least three properties, mainly those of selection, survival, and length of follow-up. Further properties may come to light when cause and effect relationships are sought through the development of models.

\section{METHOD}

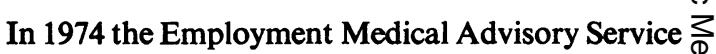
(EMAS), with the co-operation of the management ? and staff of the four companies involved in the $\vec{F}$ manufacture of polyvinyl chloride (PVC), mounted $\stackrel{\text { ? }}{?}$ a prospective mortality study aimed at covering all workers who had been or would be employed in the industry in Great Britain. Although complete records $\vec{\nabla}$ were not always available, it was thought that the $\varrho$ overall picture was reasonably representative.

Our report of this study (Fox and Collier, 1977), $\vec{\circ}$ covering the period 1940-74 describes how more $\overrightarrow{\vec{H}}$ than 7000 men were employed at some time during this period on processes which resulted in possible $\overrightarrow{\times}$ exposure to vinyl chloride monomer (VCM). The $\frac{\rho}{+}$ industry is one which expanded rapidly after the $\omega_{0}$ second world war. The work force in 1974 represented is more than $50 \%$ of persons who had at some time $N$ been exposed to VCM in the manufacture of PVC in Great Britain. Although no accurate measures of $\stackrel{\circ}{\supset}$ exposure levels are available the indications are thät $\vec{\square}$ these have changed considerably since about $196 \%$ as about that time attention was being paid to the incidence of acro-osteolysis among workers exposeg $\bar{\sigma}$ to high concentrations of VCM. The threshold limft $\stackrel{\Phi}{-}$ value for VCM was reduced from $1000 \mathrm{ppm}$ to $2 \mathrm{~g} \vec{\omega}$ $\mathrm{ppm}$. As a result of conclusive evidence relating the exposure of workers to VCM to the subsequent development of a rare liver cancer (angiosarcoma), the standards that had been adopted were further reduced to $25 \mathrm{ppm}$ (time weighted average with a 50 ppm ceiling) and subsequently to $10 \mathrm{ppm}$ (time weighted average with a 30 ppm ceiling).

These dynamic changes were of fundamental importance in terms of the interpretation of the results of the study. When the total study population was considered some 393 deaths were observed compared with $521 \cdot 22$ expected on the basis of age-standardized death rates for all men in England ${ }_{\sigma}^{+}$ and $W$ ales. The person years at risk calculations were 3 . based on five-year age groups. The overall standardized mortality ratio (SMR) 75.4 is significantly below 100 although, as indicated above, this음 is not altogether surprising because approximately $\supset$ half of the population entered the industry within the period 1965-74, and were consequently fit for $N$ work. The 'healthy population selection effect' and the 'survivor population effect' described in detail more than 100 years ago by Ogle and referred to more recently in the discussion that followed Goldsmith's letter (Goldsmith, 1975) have been widely recognized by epidemiologists. Since this? study of VCM workers covers an almost complete 
population of persons exposed, it affords an almost unique opportunity to obtain these measures for one industrial group.

\section{RESULTS}

In our report of this study (Fox and Collier, 1977) we stated that if the population were separated into cohorts according to the quinquennium of entry into the industry, those men who entered more recently would have lower overall mortality ratios than would those men who entered earlier. Similar trends were observed for all cancers and for circulatory disease when studied separately. By separating the observed and expected deaths according to year in which death occurred, we showed that the reduction in SMR was associated not with cohort definition but with the length of time the cohort was followed-up and therefore the length of time since the individual entered the industry. The analysis by length of time the cohort had been followed when divided into five-year periods, indicated that the SMR in the first five years of study might be as low as $\mathbf{4 0} \cdot 5$. Except for a slight drop in SMR between 20 years' and 29 years' follow-up the increase in SMR associated with longer follow-up is consistent, rising to 106.5 after 30-34 years.

Table I gives the observed and expected deaths within the first four years, five to nine years, ten to fourteen years, and 15 years or more since entry into the industry. The SMR is seen to rise consistently from $37 \cdot 4$ for the first five years of study to $94 \cdot 2$ for 15 years or more. The four age groups are considered separately in Table I; the rise in SMR associated with increased length of time since entering the industry is seen in each of these age groups. The ratio of SMR for $15+$ years to that for less than four years is greater in the older age groups (55 to 74 years) than in the younger groups ( 25 to 54 years). The ratio of SMR for five to nine years to that of up to four years is however greater in the younger than the older age groups. Although in the 65 to 74-year group particularly, the numbers are small the analysis suggests that the healthy population effect is greater in the older age groups and lasts longer.

Table II analyses the same deaths according to cause. The same trend of rising SMR with increased length of time since entering the industry is seen for cancer, circulatory disease, and respiratory disease. The SMR for respiratory disease was affected more than it was for cancer and circulatory disease. The effect also lasts longer for respiratory disease than for cancer and circulatory disease, based on a comparison of SMRs for those dying within 5-14 years of entering the industry. The SMR for cancer is consistently between $7 \%$ and $20 \%$ higher than for all deaths.

A survivor population effect is more difficult to measure than the healthy population effect. The latter relates to the fitness of a group of men at one point in time, the time when they enter the industry, whereas the survivor population effect is continuously altered by the dynamic movements within and out of the industry. Although most people who change jobs within the industry or leave the industry do so for reasons unrelated to health, there are a number who change because they are not fit enough to continue in their present job or possibly because they consider their employment is affecting their health. Those people who enter the industry have a reduced SMR because of the healthy population selection

TABLE I

OBSERVED AND EXPECTED DEATHS BY AGE AND LENGTH OF TIME SINCE ENTERING THE INDUSTRY

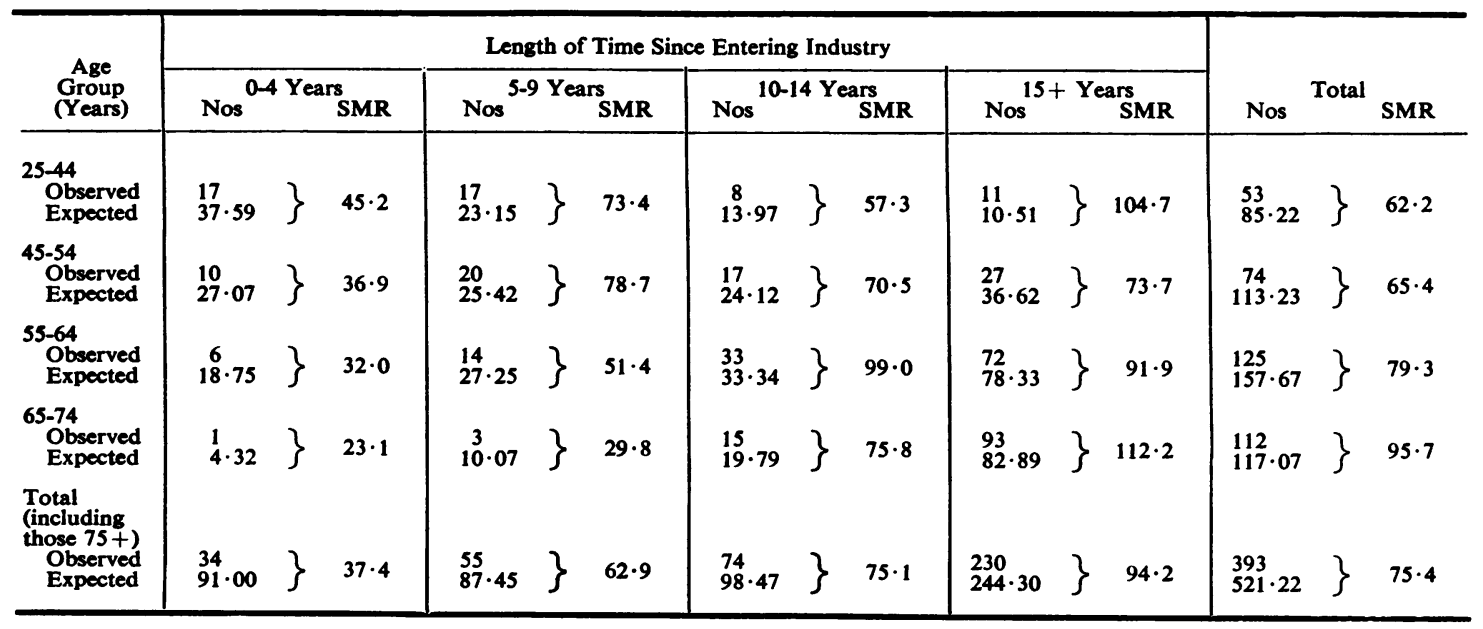


TABLE II OBSERVED AND EXPECTED DEATHS BY CAUSE AND LENGTH OF TIME SINCE ENTERING THE INDUSTRY

\begin{tabular}{|c|c|c|c|c|c|c|c|c|c|c|c|}
\hline \multirow[b]{2}{*}{$\begin{array}{l}\text { Cause of } \\
\text { Death }\end{array}$} & \multicolumn{8}{|c|}{ Length of Time Since Entering Industry } & \multirow{2}{*}{\multicolumn{2}{|c|}{ Total }} & \multirow[b]{2}{*}{ SMR } \\
\hline & Nos ${ }^{0}$ & SMR & Nos & SMR & $\begin{array}{l}10 \\
\text { Nos }\end{array}$ & SMR & $\operatorname{Nos}^{15}$ & $\stackrel{\text { ars }}{\text { SMR }}$ & & & \\
\hline $\begin{array}{c}\text { All causes } \\
\text { Observed } \\
\text { Expected }\end{array}$ & $\begin{array}{l}34 \\
91 \cdot 00\end{array}$ & $37 \cdot 4$ & $\begin{array}{l}55 \\
87 \cdot 45\end{array}$ & $62 \cdot 9$ & $\begin{array}{l}74 \\
98 \cdot 47\end{array}$ & $75 \cdot 1$ & $\begin{array}{l}230 \\
244 \cdot 20\end{array}$ & $94 \cdot 2$ & $\begin{array}{l}393 \\
521 \cdot 22\end{array}$ & & $75 \cdot 4$ \\
\hline $\begin{array}{l}\text { All cancers } \\
\text { Observed } \\
\text { Expected }\end{array}$ & $\stackrel{9}{20} \cdot 23$ & $44 \cdot 5$ & $\begin{array}{l}15 \\
21 \cdot 25\end{array}$ & $70 \cdot 6$ & $\begin{array}{l}23 \\
24 \cdot 48\end{array}$ & $94 \cdot 0$ & $\begin{array}{l}68 \\
60 \cdot 81\end{array}$ & $111 \cdot 8$ & $\begin{array}{l}115 \\
126 \cdot 77\end{array}$ & & $90 \cdot 7$ \\
\hline $\begin{array}{l}\text { Circulatory } \\
\text { disease } \\
\text { Observed } \\
\text { Expected }\end{array}$ & $\begin{array}{c}7 \\
32 \cdot 49\end{array}$ & $21 \cdot 5$ & $\begin{array}{l}25 \\
35 \cdot 56\end{array}$ & $70 \cdot 3$ & $\begin{array}{l}38 \\
44 \cdot 87\end{array}$ & $84 \cdot 7$ & $\begin{array}{l}110 \\
121 \cdot 26\end{array}$ & $90 \cdot 7$ & ${ }_{234}^{180} \cdot 18$ & 3 & $76 \cdot 9$ \\
\hline $\begin{array}{l}\text { Respiratory } \\
\text { disease } \\
\text { Observed } \\
\text { Expected }\end{array}$ & 2.59 & 20.9 & $\stackrel{4}{10 \cdot 31}$ & $38 \cdot 8$ & $\stackrel{4}{12 \cdot 76}$ & $31 \cdot 3$ & $\begin{array}{l}32 \\
34 \cdot 43\end{array}$ & $93 \cdot 0$ & $\begin{array}{l}42 \\
67.09\end{array}$ & \} & $62 \cdot 6$ \\
\hline
\end{tabular}

effect and this cannot easily be separated from the ensuing effect of their continuing in the industry.

It was indicated in our report (Fox and Collier, 1977) that the healthy population selection effect may be considered small 15 years after entry to the industry. The survivor population effect for men who were alive 15 years after entry was measured by comparing the mortality patterns of those who had left the industry before the 15 years were completed with those for men still in the industry 15 years after entering. The SMR for past workers including retired workers was $108 \cdot 4$ compared with $74 \cdot 0$ for those employees who were still in the industry.

In Tables III and IV this analysis has been taken one stage further to see whether or not the 15-year survivor population effect is related to age and/or cause of death. Table III shows that the reduction in SMRs is greatest in younger men. In those over 75 years of age the effect may be the other way round, although the SMR for those currently employed after 15 years is based on only four deaths.

Table IV shows that the SMRs for all cancers, lung cancer, circulatory disease, and respiratory disease are affected, but that lung cancer and respiratory disease appear most affected.

The effects measured in Tables III and IV, although almost free from healthy population selection effect, are not free from the effect of exposure. We argue, for example, that those persons who survive in the industry are, in general, fitter than those who leave. This may be true at the time they leave. The alternative argument for diseases related to length of exposure is that people who survive 15 years in the industry are exposed to the industry's hazards for 15 years, whereas those who leave experience shorter exposures.

In our report (Fox and Collier, 1977) we examined the deaths of men who entered the industry between
1940 and 1959 and who were alive 15 years later. These deaths were analysed according to the length of time spent in the industry. Although not in the 1940-44 cohort, overall there was a weak positive association between SMR and length of exposure?

In Tables V and VI, those men described in Tables III and IV as 'past employees' have been subdivided according to the length of time they spent in the induse try. The selection effect is minimized and the survivo effect significantly reduced because the men studied. were all alive 15 years after entry and had all left the industry. The residual survivor effect is associated with the length of time since people left the industry. Overall this analysis suggests a weak association between increased length of exposure and mortality rate. Table $\mathrm{V}$ indicates that the low rate in those exposed for less than five years was due to a low rate for men aged 75 and over (nine observed, 18.50 expected). The only indications of an excess with increased exposure are in the 55-64-year age group. Table VI suggests that this increase in SMR associated with length of time in the industry may be due to such an association for circulatory disease. In our report (Fox and Collier, 1977) we concluded that this was only limited evidence suggesting an association between mortality rate and increased length of exposure. Some such relationships may be discovered when more data are available but it should be remembered that the only excess found so far in this study to be associated with exposure to vinyl chloride was one of liver cancer. Since this is a relatively uncommon cause of death it is unlikely to be apparent when either all deaths or all cancers (as a group) are studied.

\section{Discussion}

The effects on man of exposure to many of the chemicals used widely throughout industry have not 
TABLE III

OBSERVED AND EXPECTED DEATHS BY AGE FOR CURRENT AND PAST EMPLOYEES ALIVE 15 YEARS AFTER ENTRY INTO INDUSTRY

\begin{tabular}{|c|c|c|c|c|c|c|}
\hline \multirow{2}{*}{$\begin{array}{c}\text { Age } \\
\text { Group } \\
\text { (years) }\end{array}$} & \multicolumn{3}{|c|}{ Current Employees } & \multicolumn{3}{|c|}{ Past Employees } \\
\hline & Observed & Expected & SMR & Observed & Expected & SMR \\
\hline $\begin{array}{l}25-44 \\
45-54 \\
55-64 \\
65-74 \\
75+ \\
\end{array}$ & $\begin{array}{r}3 \\
12 \\
26 \\
30 \\
4\end{array}$ & $\begin{array}{r}6 \cdot 07 \\
20 \cdot 83 \\
40 \cdot 80 \\
30 \cdot 79 \\
2 \cdot 80\end{array}$ & $\begin{array}{r}49 \\
58 \\
64 \\
97 \\
139\end{array}$ & $\begin{array}{r}8 \\
15 \\
45 \\
64 \\
23\end{array}$ & $\begin{array}{r}4 \cdot 43 \\
15.79 \\
37.54 \\
52 \cdot 08 \\
33.07\end{array}$ & $\begin{array}{r}181 \\
95 \\
120 \\
123 \\
70\end{array}$ \\
\hline Total & 75 & $101 \cdot 36$ & $74 \cdot 0$ & 155 & $142 \cdot 94$ & $108 \cdot 4$ \\
\hline
\end{tabular}

TABLE IV

OBSERVED AND EXPECTED DEATHS BY CAUSE FOR CURRENT AND PAST EMPLOYEES ALIVE 15 YEARS AFTER ENTRY INTO INDUSTRY

\begin{tabular}{l|c|c|c|c|c|c}
\hline \multirow{2}{*}{ Cause } & \multicolumn{3}{c|}{ Current Employees } & \multicolumn{3}{c}{ Past Employees } \\
\cline { 2 - 7 } & Observed & Expected & SMR & Observed & Expected & SMR \\
\hline All cancers & 24 & $26 \cdot 99$ & 89 & 44 & $33 \cdot 81$ & 130 \\
Lung cancer & 6 & $11 \cdot 91$ & 50 & 22 & $14 \cdot 10$ & 156 \\
Circulatory disease & 37 & $49 \cdot 24$ & 75 & 73 & 101 & 111 \\
Respiratory disease & 8 & $12 \cdot 81$ & 63 & 24 & $142 \cdot 94$ & $108 \cdot 4$ \\
\hline All deaths & 75 & $101 \cdot 36$ & $74 \cdot 0$ & 155 & & 13 \\
\hline
\end{tabular}

TABLE V

OBSERVED AND EXPECTED DEATHS BY AGE AND LENGTH OF EXPOSURE FOR PAST EMPLOYEES ALIVE 15 YEARS AFTER ENTRY

\begin{tabular}{|c|c|c|c|c|c|c|c|c|c|}
\hline \multirow{3}{*}{$\begin{array}{c}\text { Age } \\
\text { Group } \\
\text { (years) }\end{array}$} & \multicolumn{9}{|c|}{ Length of Exposure } \\
\hline & \multicolumn{3}{|c|}{ 0-4 Years } & \multicolumn{3}{|c|}{ 5-9 Years } & \multicolumn{3}{|c|}{ 10-14 Years } \\
\hline & Observed & Expected & SMR & Observed & Expected & SMR & Observed & Expected & SMR \\
\hline $\begin{array}{l}15-44 \\
45-54 \\
55-64 \\
65-74 \\
75+\end{array}$ & $\begin{array}{r}4 \\
13 \\
27 \\
40 \\
9\end{array}$ & $\begin{array}{r}2 \cdot 92 \\
10 \cdot 97 \\
25 \cdot 61 \\
31 \cdot 72 \\
18 \cdot 50\end{array}$ & $\begin{array}{r}137.0 \\
118 \cdot 5 \\
105 \cdot 3 \\
126 \cdot 1 \\
48 \cdot 6\end{array}$ & $\begin{array}{r}3 \\
2 \\
11 \\
8 \\
8\end{array}$ & $\begin{array}{l}1 \cdot 05 \\
3 \cdot 21 \\
8 \cdot 16 \\
7 \cdot 49 \\
7 \cdot 67\end{array}$ & $\begin{array}{r}285 \cdot 7 \\
62 \cdot 3 \\
134 \cdot 8 \\
106 \cdot 8 \\
104 \cdot 3\end{array}$ & $\begin{array}{r}1 \\
7 \\
16 \\
6\end{array}$ & $\begin{array}{r}0.55 \\
1.61 \\
3.78 \\
12.88 \\
6.91\end{array}$ & $\begin{array}{r}181 \cdot 8 \\
185 \cdot 2 \\
124 \cdot 2 \\
86.9\end{array}$ \\
\hline All deaths & 93 & $89 \cdot 64$ & $103 \cdot 7$ & 32 & $27 \cdot 59$ & $116 \cdot 0$ & 30 & $25 \cdot 72$ & $116 \cdot 6$ \\
\hline
\end{tabular}

TABLE VI

OBSERVED AND EXPECTED DEATHS FROM MAJOR CAUSES BY LENGTH OF EXPOSURE FOR PAST EMPLOYEES ALIVE 15 YEARS AFTER ENTRY

\begin{tabular}{|c|c|c|c|c|c|c|c|c|c|}
\hline \multirow{3}{*}{$\begin{array}{l}\text { Causes of } \\
\text { Death }\end{array}$} & \multicolumn{9}{|c|}{ Length of Exposure } \\
\hline & \multicolumn{3}{|c|}{$0-4$ Years } & \multicolumn{3}{|c|}{ 5-9 Years } & \multicolumn{3}{|c|}{ 10-14 Years } \\
\hline & Observed & Expected & SMR & Observed & Expected & SMR & Observed & Expected & SMR \\
\hline \multirow{3}{*}{$\begin{array}{l}\text { All cancers } \\
\text { Lung cancer } \\
\text { Circulatory } \\
\text { disease } \\
\text { Respiratory } \\
\text { disease }\end{array}$} & $\begin{array}{l}30 \\
16\end{array}$ & $\begin{array}{r}21 \cdot 63 \\
9 \cdot 14\end{array}$ & $\begin{array}{l}138 \cdot 7 \\
175 \cdot 0\end{array}$ & $\begin{array}{l}9 \\
3\end{array}$ & $\begin{array}{l}6 \cdot 40 \\
2 \cdot 63\end{array}$ & $\begin{array}{l}140 \cdot 6 \\
114 \cdot 2\end{array}$ & $\begin{array}{l}5 \\
3\end{array}$ & $\begin{array}{l}5 \cdot 78 \\
2 \cdot 34\end{array}$ & $\begin{array}{r}86 \cdot 5 \\
128 \cdot 4\end{array}$ \\
\hline & 40 & $44 \cdot 98$ & 88.9 & 16 & $13 \cdot 90$ & $115 \cdot 1$ & 17 & $13 \cdot 13$ & $129 \cdot 5$ \\
\hline & 14 & $13 \cdot 27$ & $105 \cdot 5$ & 6 & $4 \cdot 13$ & $145 \cdot 2$ & 4 & $4 \cdot 23$ & $94 \cdot 6$ \\
\hline All deaths & 93 & $89 \cdot 64$ & $103 \cdot 7$ & 32 & $27 \cdot 59$ & $116 \cdot 0$ & 30 & $25 \cdot 72$ & $116 \cdot 6$ \\
\hline
\end{tabular}


been adequately ascertained. For some chemicals no measures of man's response to exposure have been obtained. Although others have been shown to be hazardous if men are exposed to high concentrations, much further research is required before the effects arising from exposures to lower concentrations are understood. For those chemicals for which methods of control have been recommended, the effectiveness of this control must be monitored by seeking medical as well as environmental indications of a continuing hazard.

The design of a study must depend above all on its objectives in relation to these three areas of research. If it is concerned with the identification of a hazard it may concentrate on the sectors of the exposed population in which significant exposures took place long enough in the past to ensure that any effect has had time to become manifest. A study concerned with the development of the dose-response relationships may cover a wider sector of the exposed population. Another monitoring of the effectiveness of control measures can be mounted only after these have been put into effect. Such monitoring must measure not only the chemical's effect on the men exposed but also the effect of the control measure on the actual environment to which he is exposed.

This survey is unique in that it is restricted to all men who have at some time been employed in one industry in one country. Its main objective was to put into perspective the hazards associated with work in that industry. The study confirmed the association between high exposures to VCM and mortality from liver cancer, in particular from angiosarcoma. Little evidence was found to support the suggestion that other cancers, in particular of the brain or lung, are associated with exposure to VCM. We have now considered the observations in greater depth to explain the low mortality rates that were previously reported. Although the selection problems associated with studying occupational groups had often been referred to, no serious attempt had previously been made to quantify these.

The result of this analysis shows clearly that in this industry the death rates depended on the selection of people fit for work into industry, their continuing employment in the industry, and the length of time that they had been studied. These factors affect all age groups (except for men over 75 years) and all cause groups that were considered. The impact appeared to be greater in younger men and was more marked for respiratory disease and lung cancer (for the survivor effect) than for circulatory disease and all cancers (as a group).

The use of mathematical models is suggested as an alternative method for analysing mortality studies; this is the natural extension of the work described by Knox (1973). As studies develop covering persons exposed to lower levels and following-up people who? leave the industry after limited exposures, this $\nRightarrow$ approach will provide the most useful way in which $\stackrel{\text { ? }}{+}$ a particular problem can be studied. Measures of the effect of selection, survival, and length of follow-up should be incorporated into any detailed model that is developed.

Dr C. J. S. Gauvain advised in the planning of this. project and Dr A. M. Adelstein, Dr M. Greenberg, and $\vec{\overrightarrow{ }}$ Dr P. J. Baxter offered valuable guidance in drafting $\omega$ this paper. No study such as this could have beenत conducted without the assistance and co-operation of the industry and unions involved. The EMAS Surveyi Control Section administered the survey, individual companies identified people who had worked in thisin industry, and the Office of Population Censuses and Surveys obtained and coded all death certificates.

Requests for reprints: Dr A. J. Fox, Office Population Censuses and Surveys, Medical Statisties Division, St Catherines House, 10 Kingsway, Lond $\mathbb{\&}{ }^{\mathbb{N}}$ WC2B 6JP.

\section{REFERENCES}

ENTERLine, P. E. (1975). What do we expect from occupational cohort? Not uniformly true for each cause of death. J. occup. Med., 17, 127.

FARR, W. (1864). Letter to the Registrar-General on the mortality in the registration districts of England during $\mathbb{Q}$ the 10 years 1851-60. Supplement to the 25th Annual Report of the Registrar General of Births, Deaths, and Marriages, in England, p. xxxv.

Fox, A. J. and Collier, P. F. (1977). Mortality experience of workers exposed to vinyl chloride monomer in the manufacture of polyvinyl chlorided in Great Britain. Brit. J. industr. Med., 34 (in press).

GafFREY, W. R. (1975). What do we expect from an 3 occupational cohort? Cause specific mortality. J.occup Med., 17, 128.

GolDSMrTH, J. R. (1975). What do we expect from an occupational cohort? J. occup. Med., 17, 126.

KNox, E. G. (1973). Computer simulation of industrial hazards. Brit. J. industr. Med., 30, 54.

MCMichael, A. J., HAYNes, S. G., and Tyroler, H. A. (1975). What do we expect from an occupational cohort? Observations on the evaluation of occupationalo mortality data. J. occup. Med., 17, 128.

OGLE, W. (1885). Letter to the Registrar-General on the mortality in the registration districts of Englando and Wales during the ten years 1871-80. Supplemente to the 45th Annual Report of the Registrar General of? Births, Deaths, and Marriages, in England, p. xxiii. 